\title{
TRIPOLI NO SUBGRUPO IRATI: A OCORRÊNCIA DE IPEÚNA, ESTADO DE SÃO PAULO
}

\author{
JORGE KAZUO YAMAMOTO ${ }^{1}$, TARCÍSIO JOSÉ MONTANHEIRO ${ }^{2} \&$ JORGE HACHIRO $^{1}$
}

\begin{abstract}
TRIPOLIINTHE ITATI SUBGROUP: THE OCCURRENCE OFIPEÚNA, STATE OF SÃO PAULO Tripolis are rocks composed essentially of microcrystalline quartz originated from final stages of silicified dolomitic limestones, where carbonates had been removed by weathering processes. Studies developed on a tripoli occurrence of the Ipeúna Member (Irati Subgroup), Municipality of Ipeúna, State of São Paulo, corroborate its origin from silicification of limestones. In this occurrence, tripoli replaces some layers of dolomitic limestone and interstratified couples limestone-shale. Experimental acid dissolution on silicified dolomitic limestone showed that tripoli formation is possible from partial silicification $\left(10-15 \% \mathrm{SiO}_{2}\right)$. The diagenetic process is proposed in this paper as responsible for silicification of dolomitic limestone of the Ipeúna Member, due to fluids enriched in $\mathrm{Si}$ expelled from crystalline structures of clay minerals belonging to the smectite group. However, a hydrotermal contribution is not totally disregarded for the partial silicification of dolomitic limestones of the Ipeúna Member derived from Serra Geral magmatism.
\end{abstract}

Keywords: trípoli, Ipeúna Member, Irati Subgroup.

\begin{abstract}
Resumo Trípolis são rochas compostas essencialmente por quartzo microcristalino, cuja origem é atribuída aos estágios finais de intemperismo de rochas carbonáticas silicificadas, tendo os carbonatos sido removidos por processos intempéricos. Os estudos realizados sobre uma ocorrência de trípoli no Membro Ipeúna (Subgrupo Irati) no município homônimo, Estado de São Paulo, comprovam a origem desta rocha, a partir da silicificação de rochas carbonáticas. Nesta ocorrência, parte das camadas de calcário dolomítico, dos pares interestratificados calcário-folhelho, está representada por trípoli. Estudos experimentais de ataque ácido em calcários dolomíticos silicificados demonstraram ser possível a formação de trípoli, a partir de uma silicificação parcial (10-15\% de $\mathrm{SiO}_{2}$ ). Propõe-se neste trabalho o processo diagenético para silicificação de calcários dolomíticos do Membro Ipeúna, a partir de fluidos ricos em Si mobilizados das estruturas cristalinas de argilominerais do grupo das esmectitas, contidos nos folhelhos. Entretanto, não é totalmente descartada uma contribuição hidrotermal, para a silicificação parcial de calcários dolomíticos do Membro Ipeúna, derivada do magmatismo Serra Geral.
\end{abstract}

Palavras-chave: Trípoli, Membro Ipeúna, Subgrupo Irati.

INTRODUÇÃO O trípoli, numa definição em sentido amplo,é uma rocha formada em vários estágios de agregação (Bolen 1996), constituída quase essencialmente de quartzo microcristalino, com granulação variando de I a $10 \mathrm{~mm}$. Segundo este autor, os trípolis comerciais são materiais sílico-aluminosos, que contêm 98 a 99\% de sílica, alumina contida em argilominerais e óxido de ferro, e são utilizados como matéria-prima para a fabricação de abrasivos, massas de polimento e cargas minerais inertes quimicamente estáveis. Para Metcalf (1949), o trípoli é o produto final do intemperismo de calcários silicosos, calcários silexíticos ou silexitos; em outras palavras, é o remanescente desses tipos de rochas, após a remoção do carbonato de cálcio e magnésio.

Originariamente o nome trípoli designava os produtos silicosos encontrados no norte da África, nas proximidades da Cidade de Trípoli - Líbia (Quirk \& Bates 1978). Segundo esses autores, atribuiu-se também o mesmo nome, devido à aparente semelhança, aos depósitos de silica microcristalina, formados por silica altamente pura $\left(\mathrm{SiO}_{2}\right)$, porosa, leve e friável, descobertos por volta de 1800 nas proximidades de Seneca, no Missouri (EUA). No entanto, estudos posteriores mostraram a diferença entre estes produtos: o da África do Norte, é constituído de esqueletos de diatomáceas (tripolita), ao passo que o do Missouri passou a ser chamado de trípoli (Quirk \& Bates 1978).

No Estado de São Paulo, trípoli é citado pela primeira vez em Knecht (1940), referindo suas ocorrências nos sedimentos do Grupo Estrada Nova, nas localidades de Fartura, Bonsucesso, Angatuba, Guareí, Tatuí, Conchas, Piracicaba, São Pedro, Rio Claro, Limeira, Araras e Piraçununga.

Recentemente, a presença de sílica microcristalina - trípoli - foi assinalada por Riccomini et al. (1997) em rochas sedimentares permianas do topo da Formação Tatuí, na região de Rio ClaroIpeúna-Piracicaba, e, mais recentemente, Montanheiro et al. (1999) também citaram outras ocorrências dele, associadas, porém, às rochas do Subgrupo Irati.

Este trabalho apresenta os resultados do estudo sobre uma ocorrência de trípoli derivada de calcários dolomíticos do topo da Formação Assistência (Membro Ipeúna) do Subgrupo Irati, descoberta que ficou inserida nos trabalhos de prospecção estratégica de materiais pozolânicos desenvolvidos por Montanheiro (1999).

CONTEXTOGEOLÓGICODA ÁREADEESTUDO Aáreade estudo insere-se no contexto geológico do Anticlinal de Pitanga (Riccomini 1995), onde ocorrem as rochas sedimentares neopaleozóicas do Grupo Tubarão (Subgrupo Itararé e Formação

\footnotetext{
I - Departamento de Geologia Sedimentar e Ambiental, Instituto de Geociências, USP, Rua do Lago 562, 05508-900, São Paulo, SP. e-mail: jkyamamo@usp.br. 2 - Instituto Geológico, Secretaria do Meio Ambiente do Estado de São Paulo, Av. Miguel Stéfano 3900, 04301-903, São Paulo, SP. e-mail: tjmonta@igeologico.sp.gov.br
} 
Tatuí) e do Grupo Passa Dois (Subgrupo Irati e Formação Corumbataí), além das rochas mesozóicas do Grupo São Bento (formações Pirambóia, Botucatu e Serra Geral), segundo Riccomini et al. (1997). Estas unidades são recobertas por depósitos cenozóicos da Formação Rio Claro. O mapa geológico ilustra a distribuição das unidades geológicas da região de Ipeúna, exceto as formações Botucatu e Serra Geral (Fig. 1).

O Subgrupo Irati, segundo a subdivisão proposta por Hachiro et al. (1993), é representado, na base, pela Formação Taquaral e, no topo, pela Formação Assistência.

A Formação Taquaral é constituída por rochas sedimentares essencialmente pelíticas: argilitos, folhelhos de cor cinza-clara a escura e siltitos. Essas camadas pelíticas contêm delgadas intercalações lenticulares de rochas carbonáticas e níveis de sílex (Hachiro 1996).

A Formação Assistência foi subdividida (Hachiro et al. 1993) em Membro Morro do Alto (base) e Membro Ipeúna (topo). O Membro Morro do Alto é composto, na base, de calcilutitos de cor acastanhada, intercalados em folhelhos negros e betuminosos com predominância, na parte intermediária, de folhelhos betuminosos cinza-escuros a negros (Hachiro 1996) e, na parte superior, folhelhos siltosos cinza e lamitos cinza-esverdeados. O Membro Ipeúna, segundo o mesmo autor, inicia-se com um banco dolomítico, constituído por dololutitos laminados e doloarenitos finos a médios, e apresenta, na parte intermediária, delgados e regulares pares alternados de folhelho/calcário, os quais se tornam mais espessos em direção ao topo.

OTRÍPOLI DE IPEÚNA Foram reconhecidas duas ocorrências de trípoli no Membro Ipeúna, na região da cidade homônima. A primeira delas (TM-321) no talude de cava de uma mina de calcário abandonada, localizada ao norte. Ali, na parte superior deste talude, foi possível distinguir um pacote sedimentar de cerca de 1,6 m correspondendo ao topo do Membro Ipeúna, no qual se encontram três camadas de trípoli com espessuras entre 0,10 e $0,40 \mathrm{~m}$, intercaladas em calcário dolomítico e folhelhos com bonecas de sílex. A outra ocorrência (TM-248), objeto deste trabalho, situa-se a sul da cidade, na localidade conhecida como Granja Mondini. O afloramento está próximo à margem direita do Córrego Água Vermelha, num corte de aterro feito para a construção do açude (Fig. 2), o qual permitiu a amostragem detalhada e o levantamento de uma seção colunar comportando as diferentes litofácies (Fig. 3). A seção colunar da Figura 3 é uma seção típica do Membro Ipeúna com intercalações de trípoli, correspondendo a camadas originais de dolomito.

MÉTODOS ANALÍTICOS A composição mineralógica e as feições texturais das rochas sedimentares e do trípoli foram estudadas pelos métodos clássicos da microscopia óptica e microscopia eletrônica de varredura.

A composição química foi determinada pelo método da espectrometria de emissão atômica por plasma de acoplamento induzido-ICP para os seguintes óxidos: $\mathrm{SiO}_{2}, \mathrm{Al}_{2} \mathrm{O}_{3}, \mathrm{Fe}_{2} \mathrm{O}_{3}, \mathrm{MgO}$, $\mathrm{CaO}$; enquanto $\mathrm{Na}_{2} \mathrm{O}$ e $\mathrm{K}_{2} \mathrm{O}$ foram determinados por via úmida.

Seções delgadas dos calcários dolomíticos (TM-248A, TM-248B e TM-248D) foram submetidas ao ataque químico com ácido clorídrico a frio durante $24 \mathrm{~h}$, as quais foram analisadas ao microscópio eletrônico de varredura. Este ataque teve por objetivo simular os processos naturais de dissolução dos minerais carbonáticos.

RESULTADOS Petrografia Ao microscópio, as amostras de

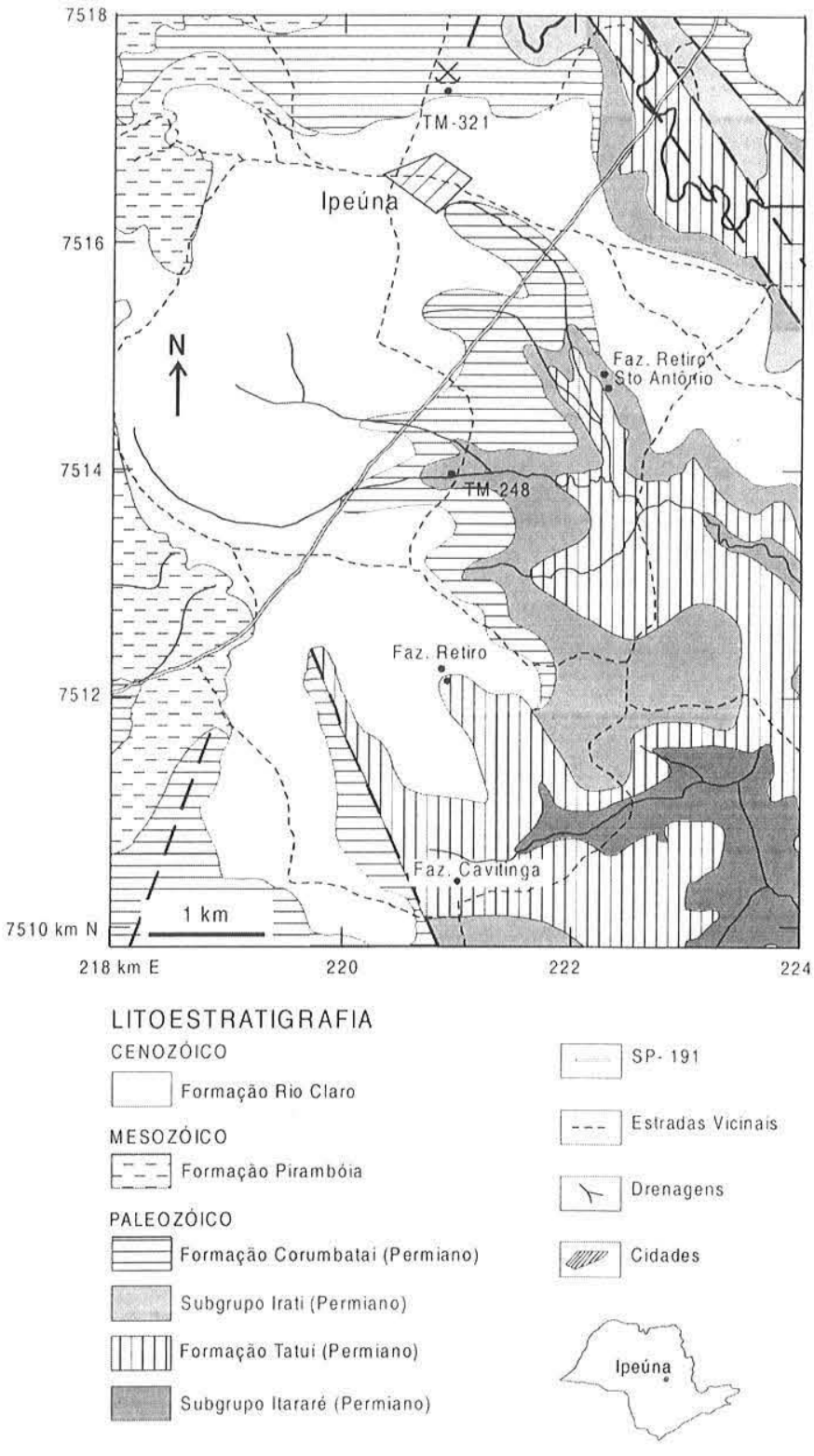

Figura 1- Mapa geológico da região de Ipeúna com a localização das ocorrências de trípoli (TM-248 e TM-321). Base geológica modificada a partir de Souza (1997).

calcário dolomítico (TM-248B e TM-248D) possuem matriz carbonática, criptocristalina a microcristalina, dolomítica, cujos cristais de dolomita parcialmente substituídos por sílica microcristalina conferem coesão à rocha. Segundo a classificação petrográfica de Folk (1962), a rocha é um micrito dolomítico, ou, ainda, segundo a classificação de Dunham (1962), um mudstone dolomítico. Segundo Hachiro (1996), análises por difração de raios $\mathrm{X}$ indicaram composição predominante de carbonatos dolomíticos.

O siltito cinza (amostra TM-248E), ao microscópio, apresenta laminação submilimétrica com alternâncias de finos leitos claros e escuros. A laminação é predominantemente plano-paralela, por vezes lenticular. As lâminas mais claras são mais siltosas e compostas de quartzo, feldspato e micas (muscovita e biotita) enquanto as lâminas mais escuras são mais argilosas e ricas em matéria 
carbonosa. Tratar-se-ia de um siltito argiloso, segundo a classificação de Folk (1974).

Composição química Os resultados das análises químicas de seis amostras de diferentes níveis da seção colunar são apresentadas na Tabela 1. Os calcários dolomíticos apresentam teores de $\mathrm{SiO}$, entre 9 e $16 \%$ e poderiam indicar o início do processo de silicificação. O trípoli (TM-248C), por sua vez, apresenta teor de apenas $76 \%$ de $\mathrm{SiO}_{2}$ o que o qualifica, do ponto de vista químico, como um material impuro em relação aos trípolis comerciais. Além disso, esta amostra ainda apresenta um teor remanescente de $\mathrm{MgO}$ $(2,18 \%)$ mostrando não ter sido total a dissolução.

Análise por microscopia eletrônica de varredura $\mathrm{A}$ amostra de trípoli é constituída por quartzo microcristalino, em diferentes estágios de agregação, subordinadamente filossilicatos e óxido de ferro. As imagens de microscopia eletrônica de varredura mostram textura esponjosa resultante da dissolução de carbonatos. A imagem exposta na Figura 4b mostra, em detalhe, a textura em box work decorrente da dissolução desses minerais.

Análises por EDS de duas áreas distintas da amostra de trípoli (TM-248C) confirmam que a composição química predominante é de $\mathrm{Si}$, complementada por $\mathrm{Al}, \mathrm{Mg}, \mathrm{K}, \mathrm{Mn}$ e Fe. Embora os resultados sejam semi-quantitativos, estas análises são compatíveis com

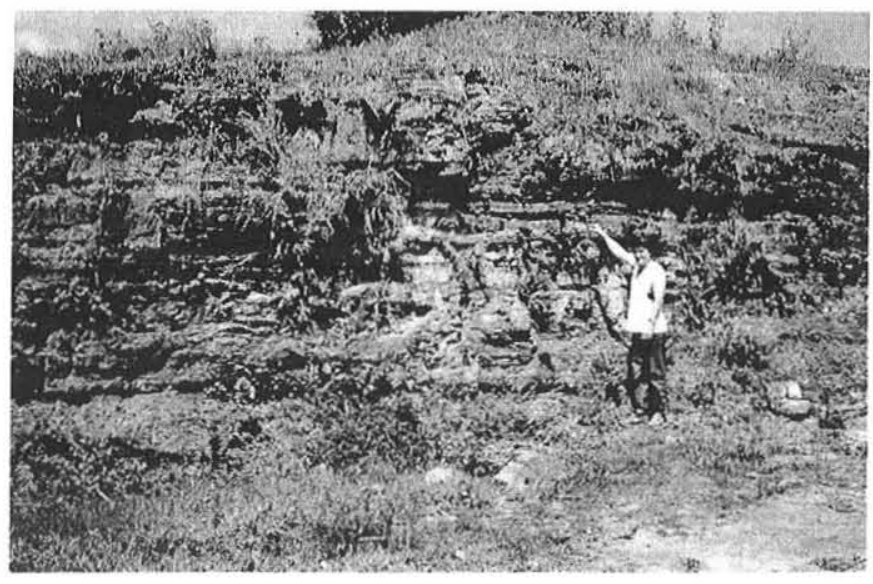

Figura 2 - Camadas de calcário dolomítico com folhelhos, intercaladas com trípoli. os apresentados na Tabela 1 .

O estudo das lâminas delgadas submetidas a ataque ácido revelou, ao microscópio eletrônico de varredura, textura esponjosa sustentada pelo quartzo microcristalino, após a dissolução dos

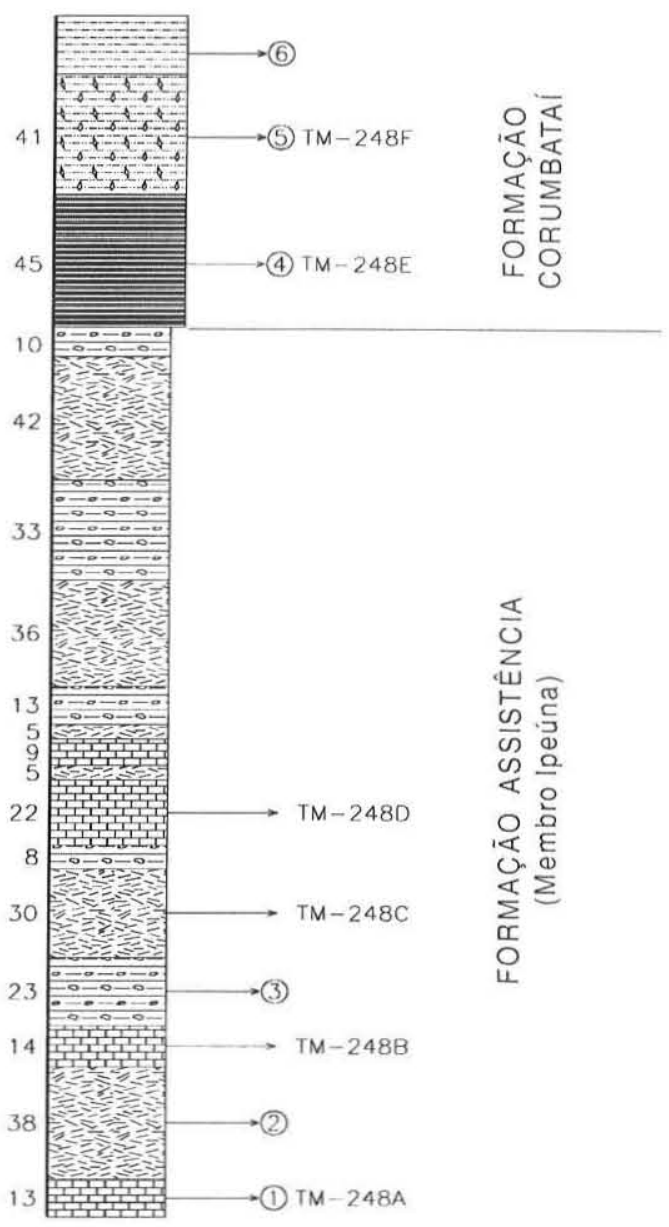

Figura 3 - Seção colunar do Membro Ipeúna, com intercalações de trípoli. Calcário dolomítico (1), trípoli (2), folhelhos com bonecas de síles (3), silitito argiloso cinza-médio (4), folhelho siltoso (5) e lamito (6). Os números à esquerda da seção indicam a espessura das camadas em $\mathrm{cm}$.

Tabela 1 - Composições químicas de amostras de diversas rochas do Membro Ipeúna (teor em \%; P.F. = perda ao fogo).

\begin{tabular}{cccccccccc}
\hline Litotipo & $\mathrm{Am}$ ostra & $\mathrm{SiO}_{2}$ & $\mathrm{Al}_{2} \mathrm{O}_{3}$ & $\mathrm{Fe}_{2} \mathrm{O}_{3}$ & $\mathrm{MgO}$ & $\mathrm{CaO}$ & $\mathrm{Na}_{2} \mathrm{O}$ & $\mathrm{K}_{2} \mathrm{O}$ & P.F. \\
\hline calcário dolomítico & $\mathrm{TM}-248 \mathrm{~A}$ & 13,32 & 0,93 & 2,8 & 15,57 & 25,65 & 0,2 & 0,31 & 40,15 \\
calcário dolomítico & $\mathrm{TM}-248 \mathrm{~B}$ & 9,32 & 1,05 & 2,4 & 15,67 & 28,08 & 0.22 & 0,33 & 41.42 \\
trípoli & $\mathrm{TM}-248 \mathrm{C}$ & 76,25 & 5,48 & 5,72 & 2,18 & 0,9 & 0,58 & 1,25 & 5.02 \\
calcário dolomítico & $\mathrm{TM}-248 \mathrm{D}$ & 16,12 & 0,69 & 4,09 & 14,09 & 25,08 & 0,12 & 0,22 & 38,15 \\
Sillito cinza & $\mathrm{TM}-248 \mathrm{E}$ & 81,5 & 2,96 & 3,95 & 0,34 & 0,38 & 0.2 & 1,31 & 8.39 \\
Folhelho siltoso & $\mathrm{TM}-248 \mathrm{~F}$ & 78,66 & 9,42 & 2,89 & 0.41 & 0,31 & 0,48 & 2,11 & 5.00 \\
\hline
\end{tabular}


carbonatos.

A imagem da amostra TM-248B mostra o contato entre um nódulo silicoso e o produto remanescente de uma matriz carbonática após ataque ácido (Fig. 5a). A análise da porção originalmente carbonática, em detalhe, revela moldes romboédricos típicos de cristais de dolomita que foram dissolvidos pela reação com o ácido clorídrico (Fig. 5b). A análise do nódulo silicoso (Fig. 5c) revela uma textura diferente da encontrada usualmente em trípolis, pois se constitui de uma massa silicosa compacta com baixa quantidade de vazios.

É importante ressaltar que o quartzo microcristalino presente na massa carbonática da rocha estudada, não é visível em seção delgada, exceto em nódulos silicosos.

Com relação ao resíduo sólido obtido após ataque com ácido clorídrico, constatou-se que é formado em grande parte por calcedônia.

O exame das características dessa calcedônia sob microscópio óptico e MEV revela a distribuição da sílica na forma de uma coalescente massa esponjosa semelhante a um tecido cheio de minúsculos poros, constituindo um arcabouço silicoso interpenetrado na rocha carbonática. A calcedônia apresenta granulação média entre 1 e 5 micra, mostra incipiente laminação

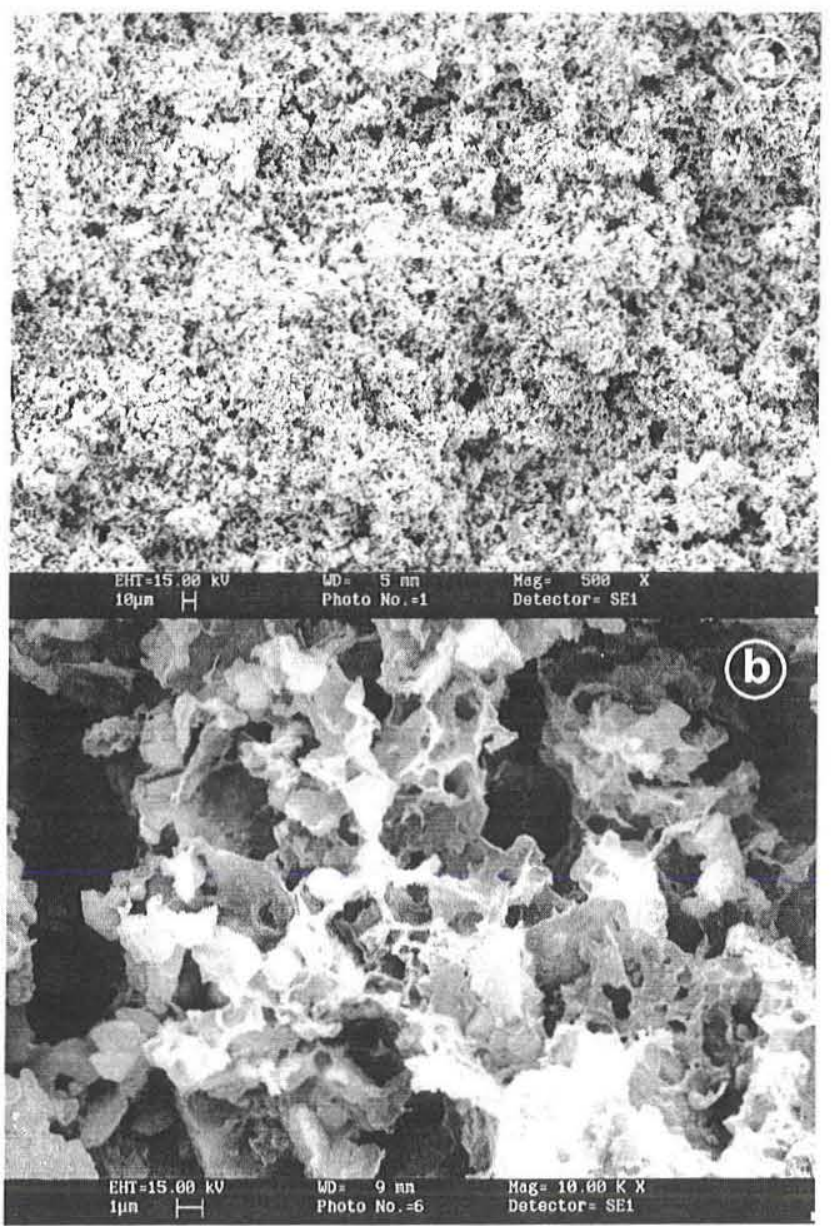

Figura 4 - Imagem de microscopia eletrônica de varredura da amostra de trípoli. Textura característica do trípoli em forma de esponja silicosa (a) e detalhe mostrando espaços vazios formados pela dissolução de carbonatos (b). concordante com a estratificação plano-paralela, sugerindo que a ocupação e precipitação da sílica ocorreram de acordo com o arranjo dos estratos carbonáticos já depositados, conforme já havia sido assinalado por Amaral (1971).

ORIGEM DA SILICIFICAÇÃO As primeiras hipóteses levan-

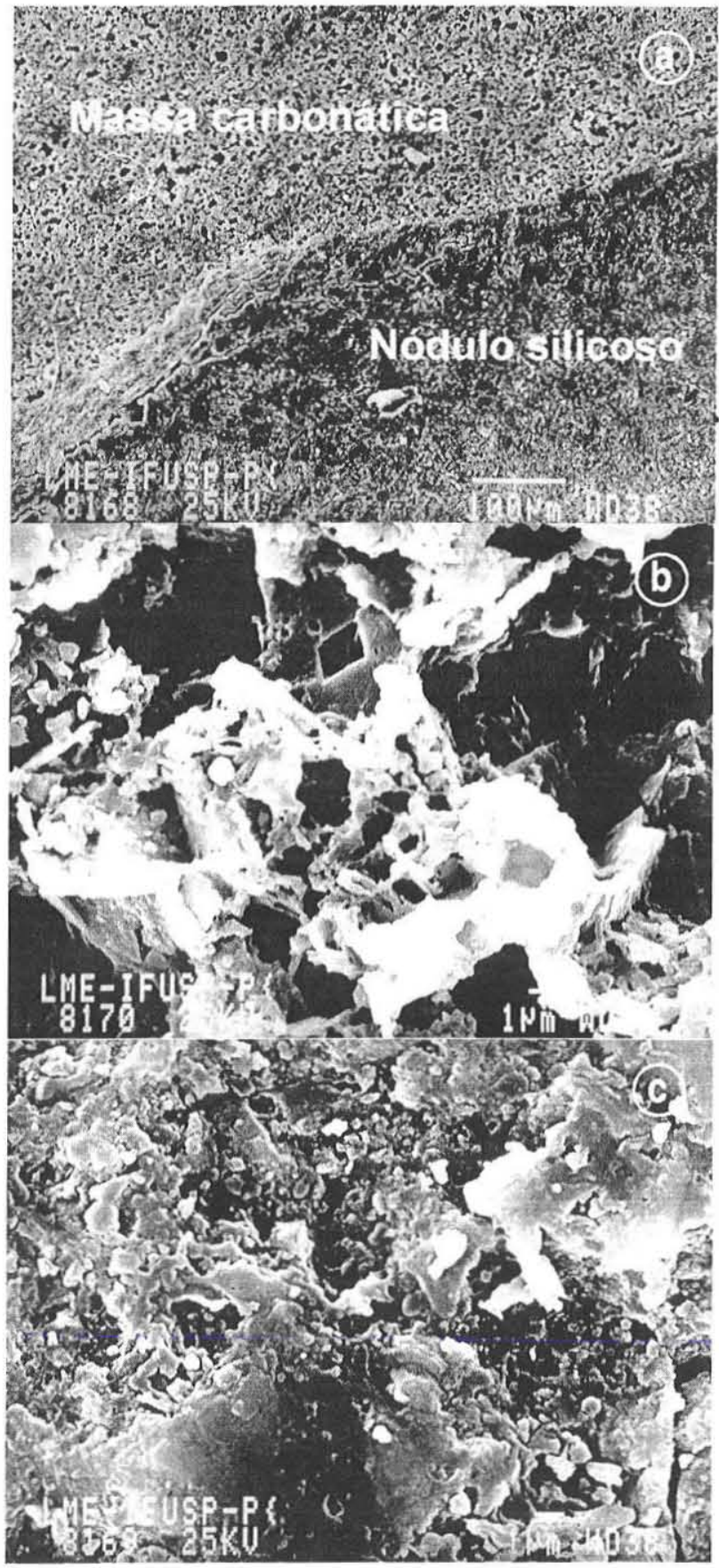

Figura 5 - Imagem de microscopia eletrônica de varredura de uma lâmina de calcário dolomítico silicificado após ataque com ácido clorídrico a 10\% durante 24 horas na interface entre um nódulo silicoso e o remanescente de uma massa carbonática (a), detalhe do remanescente da massa carbonática $(b)$ e detalhe do nódulo silicoso $(c)$. 
tadas para explicar a silicificação, dos sedimentos da Bacia do Paraná devem-se a Moraes Rego (1930), Oppenhein (1934) e Leinz (1938) que estudaram os silexitos de diversas unidades gondwânicas incluindo os do Subgrupo Irati. Segundo esses autores, a silicificação seria devida a ação de soluções silicosas, hidrotermais ou não, provenientes do magmatismo basáltico Serra Geral (Cretáceo Inferior). Essa interpretação baseia-se na presença de numerosas intrusões de diabásio nos sedimentos gondwânicos do norte da bacia.

Amaral (1971) ao aludir sobre o problema da fonte primária da sílica responsável pela silicificação de rochas do Grupo Passa Dois, considerou possível esta provir da dissolução de espículas silicosas de esponjas, localmente identificadas. No entanto, ressaltou sua pouca importância, pois não deveriam ocorrer em quantidade suficiente para formar as centenas de bilhões de toneladas de silexitos do Subgrupo Irati. Outro fato que enfraquece esta hipótese é que o ambiente deposicional do Subgrupo Irati parece ter sido bastante desfavorável à proliferação de esponjas que necessitam de águas oxigenadas e agitadas.

Riccomini et al. (1997), em trabalho sobre rochas do topo da Formação Tatuí na área de Ipeúna (SP), reconheceram ocorrências de trípoli e concreções de sílex e quartzo, cuja formação atribuíram à percolação de fluidos hidrotermais ao longo de fraturas e falhas. Tal processo teria resultado em precipitação de calcedônia e quartzo euhedral concomitantemente com a dissolução de rochas carbonáticas. Esse hidrotermalismo estaria vinculado aos estágios finais do magmatismo da Formação Serra Geral (Ki).

Consideramos que a silicificação dos dolomitos do Irati envolve processos diagenéticos de transformação de argilominerais do grupo das esmectitas em illitas (Boles \& Franks 1979 e Lahann 1980). Esses argilominerais estão invariavelmente presentes nos folhelhos dos ritmitos do topo do Membro Ipeúna. Segundo Boles \& Franks (1979), essa transformação se dá conforme a seguinte reação:

$$
\text { Esmectita }+\mathrm{K}^{+} \longrightarrow \mathrm{Illita}+\mathrm{Si}^{+4}+\mathrm{H}_{2} \mathrm{O}
$$

com perda adicional de sódio, cálcio, ferro e magnésio.

Essa transformação ao expulsar sílica e água adsorvida entre folhas da estrutura cristalina expansiva da esmectita, faz com que os estratos carbonáticos sejam percolados por soluções ricas em $\mathrm{SiO}$ e, consequientemente, silicificados.

Pode-se afirmar que a calcedônia presente em grande quantidade nos dolomitos do Irati, como resíduo remanescente insolúvel (após dissolução dos carbonatos) seria originária de soluções autigênicas enriquecidas no interior dos folhelhos (gerados em ambiente redutor), durante o soterramento e compactação dos ritmitos do Membro Ipeúna. Isso explicaria a quantidade muito maior de sílica nos dolomitos dos pares rítmicos, quando comparados aos dolomitos subjacentes da Camada Bairrinho. Estes são mais espessos, menos tenazes, com pouco material silicoso e não comportam as intercalações de folhelhos supridores de sílica, características que os tornam aproveitáveis como corretivos de solos ácidos.

Em ambiente intempérico, a esmectita forma-se, normalmente, sob condições de clima árido e drenagem precária. Para que esses argilominerais possam preservar-se, é necessário que posteriormente venham depositar-se em águas relativamente estacionárias e ricas em íons de $\mathrm{Mg}, \mathrm{Fe}$, Ca e $\mathrm{Na}$ (Keller 1956).

Com relação à mineralogia das argilas dos pelitos da Formação Assistência, o seguinte quadro foi idealizado por Ramos \& Formoso (1975): a) a caulinita é inexistente, ou muito rara; b) outros argilominerais como a esmectita, camadas mistas illita-esmectita, illita e clorita são freqüentes. Para esses autores, a composição dos argilominerais revela que, após a sedimentação das unidades subjacentes (Palermo e Rio Bonito formadas em condições de clima úmido, fato corroborado pela frequente ocorrência de caulinita), houve mudança climática na passagem da Formação Taquaral para a Formação Assistência; fato confirmado por Hachiro (1991) que verificou a presença de brechas evaporíticas na base da unidade sobrejacente.

Durante a deposição da Formação Assistência, a incidência de clima mais árido tornou os solos das áreas-fonte bem menos drenados, favorecendo a formação da esmectita. O Mar Irati, receptáculo dos sedimentos aportados, garantiu a permanência da esmectita, uma vez que suas características coincidiam com as condições do meio de preservação assinaladas por Keller (1956).

Ao nível estratigráfico correspondente à Formação Assistência no Estado de São Paulo, Ramos \& Formoso (1975) constataram grupos de argilominerais em que se destacam esmectita $(70 \%)$ e illita $(30 \%)$. Nas frações argilosas de folhelhos, obtidas de testemunhos de poços das proximidades de Ipeúna, em Carlota Prenz (1-CP-1-SP), os argilominerais são: esmectita (70\%), illita (30\%) e clorita (traço). Rodrigues \& Quadros (1976) corroboram os autores anteriormente citados e relatam que, nos folhelhos do Irati, os argilominerais básicos são esmectita, camadas mistas illitaesmectita, illita e clorita. Amostras de calha da Formação Assistência, do poço 2-GU-3-SP, mostram teores de $20 \%$ para esmectita, $25 \%$ para camadas mistas illita-esmectita, $40 \%$ para illita e $15 \%$ para clorita.

De forma semelhante, as análises por difração de raios $\mathrm{X}$ efetuadas por IPT (1982), em amostras de superfície da região de Ipeúna (antiga Pedreira Bonanza), a fração argila apresentou composição em argilominerais com esmectita $(22 \%)$, illita ( $12 \%)$ e clorita (66\%), nos folhelhos do Membro Ipeúna, da base dos ritmitos que situam-se acima do banco dolomítico (Camada Bairrinho). E próximo ao topo dos ritmitos, esmectita (19\%), camadas mistas (31\%), illita ( $15 \%$ ) e clorita (35\%). No mesmo perfil, uma amostra do siltito que marca a passagem transicional para a Formação Corumbataí, compunha-se de esmectita (38\%), illita (22\%) e clorita (40\%).

A composição em argilominerais da Formação Assistência na região de Ipeúna e as condições paleoambientais e diagenéticas de formação desta unidade comprovam a viabilidade do mecanismo aqui proposto para a silicificação dos dolomitos. O enriquecimento em sílica e a posterior dissolução do carbonato, durante o intemperismo, foram eventos de suma importância que ora permitem esclarecer a gênese do trípoli nos depósitos dolomíticos do Subgrupo Irati.

CONSIDERAÇÕES FINAIS A ocorrência de trípoli de Ipeúna é a principal evidência que o Trípoli resulta da dissolução de carbonatos em calcários dolomíticos previamente silicificados. Observa-se que, próximo ao topo do afloramento, as camadas de calcário dolomítico são totalmente substituídas por trípoli, o qual aparece intercalado ou alternando com folhelhos negros, típicos do Subgrupo Irati.

Estudos experimentais de dissolução dos carbonatos, por meio de ataque ácido ( $\mathrm{HCl}$ a $10 \%)$, provam que o trípoli forma-se até mesmo de calcários dolomíticos silicificados com teores de apenas $10-15 \%$ de $\mathrm{SiO}_{2}$.

Com relação ao modelo de silicificação dos calcários dolomíticos do Membro Ipeúna, consideramos a hipótese diagenética como sendo a melhor, não descartando a possibilidade da contribuição de atividade hidrotermal associada ao magmatismo Serra Geral 
como proposto por Riccomini et al. (1997).

A ocorrência estudada, devido à pequena espessura das camadas de trípoli e a sua estreita associação com calcários e folhelhos, não permite a sua explotação econômica. Além disso, o trípoli de Ipeúna não representa o estágio final de dissolução e, portanto, impuro do ponto de vista químico. Entretanto, os autores têm conhecimento de outras ocorrências de trípoli (Montanheiro et al.
1999) que poderiam vir a ser viabilizadas devido às suas características físicas e químicas.

Agradecimentos À Fundação de Amparo à Pesquisa do Estado de São Paulo - FAPESP, por meio dos auxílios financeiros nos processos 95/5635-4, 95/8815-3 e 01/8059-7, e aos revisores da RBG pelas sugestões ao manuscrito.

\section{Referências}

Amaral S. E. 1971. Geologia e Petrologia da Formação Irati (Permiano) no Estado de São Paulo. Bol. Instit. Geociências e Astronomia, 2:3-81

Bolen W.P. 1996. Silica. Denver, U.S.G.S., 20p. (USGS Minerals Information)

Boles J.R. \& Franks S.G. 1979. Clay diagenesis in Wilcox Sandstones of southwest Texas: implications of smectite diagnesis of sandstone cementation. J. Sed. Pet., 49:55-70.

Dunham 1962. Classification of carbonate rocks according to depositional texture. In: Classification of carbonate rocks, Tulsa, AAPG, p.108121, (Memoir 1)

Folk R.L. 1962. Spectral subdivision of limestone types. In: Classification of carbonate rocks. Tulsa, AAPG, p.62-84, (Memoir 1)

Folk R.L. 1974. Petrology of sedimentary rocks. Austin, Hemphill Publishing Co. 182p.

Hachiro J. 1991. Litotipos, associações faciológicas e sistemas deposicionais da Formação Irati no Estado de São Paulo. Inst. de Geociências, Universidade de São Paulo, Dissertação de Mestrado, 175p.

Hachiro J. 1996. O Subgrupo Irati (Neopermiano) da Bacia do Paraná. Inst. de Geociências, Universidade de São Paulo, Tese de Doutoramento, 196p.

Hachiro J., Coimbra A.M., Matos S.L.F. 1993. O caráter cronoestratigráfico da Unidade Irati. In: IGCE/UNESP, I Simpósio sobre cronoestratigrafia da Bacia do Paraná, Resumos, p. 62-63

Instituto de Pesquisas Tecnológicas do Est. de São Paulo - IPT. 1982. Análises petrográficas e mineralógicas de rochas procedentes de Itapetininga, Laranjal Paulista, Limeira, Ipeúna, Rio Claro e Piracicaba (SP). São Paulo, IPT. (Certificado 650284)

Keller W. D. 1956. Clay minerals as influenced by environments of their formation. Bull. AAPG, 40:2689-2710.

Knecht T. 1940. Os minérios não metálicos do Estado de São Paulo. São Paulo. Instituto Geográfico e Geológico. p. 248-251, (Boletim 27).

Lahann R.W. 1980. Smectite diagenesis and sandstone cement: the effect of reaction temperature. J. Sed. Petrol., 50:755-760.

Leinz V. 1938. A silicificação nos sedimentos gondwânicos no sul do Brasil e sua origem. An. Acad. bras. Ciênc. 10: 273-295

Metcalf R.W. 1949. Tripoli. In: The Committee on Industrial Minerals
Volume, New York, American Institute of Mining and Metallurgical Engineers, p.1074-1101

Montanheiro T.J. 1999. Prospeç̧ão e caracterização de pozolanas na Bacia do Paraná. Estado de São Paulo. Inst. de Geociências. Universidade de São Paulo, Tese de Doutoramento, 226p.

Montanheiro T.J., Yamamoto J.K., Gobbo L.A. 1999. Ocorrências de Trípoli no Subgrupo Irati, Estado de São Paulo. In: SBG/Núcleos São Paulo e Rio de Janeiro/Espírito Santo, $6^{\circ}$ Simpósio de Geologia do Sudeste, Boletim de Resumos, p.156

Moraes Rego L. F. 1930. A Geologia do Petróleo no Estado de São Paulo. Serviço de Geologia e Mineração, Rio de Janeiro, DNPM, 110p. (Boletim 46)

Oppenhein V. 1934. Nota sobre o sílex (chert) no sul do Brasil. An. Acad. bras. Ciênc. VI: 83-87

Quirk W.F. \& Bates A. K. 1978. Tripoli deposits of southwest Missouri and northeast Oklahoma. In: Oklahoma, Oklahoma Geological Survey, 4p. (Circular 79)

Ramos A.N. \& Formoso M.L.L. 1975. Argilominerais das rochas sedimentares da Bacia do Paraná. Rio de Janeiro, PETROBRAS Ciência, Técnica e Petróleo, Seção de Exploração de Petróleo, 9:1-47

Riccomini, C. 1995. Tectonismo gerador e deformador dos depósitos sedimentares pós-gondvânicos da porção centro-oriental do Estado de São Paulo e áreas vizinhas. Inst. de Geociências, Universidade de São Paulo, Tese de Livre Docência, 215p.

Riccomini C., Sant'Anna L.G., Coimbra A. M. 1997. Sílica microcristalina (trípoli) em rochas sedimentares permianas do flanco leste da Bacia do Paraná, Estado de São Paulo, Brasil. Rev. Bras. Geoc., 27:395-402

Rodrigues R. \& Quadros L.P. 1976. Mineralogia de argilas e teor de boro das formações paleozóicas da Bacia do Paraná. In: SBG, Cong. Bras. Geol., 29, Ouro preto, Anais, 2:351-380

Souza M.O.L. 1997. Caracterização estrutural do Domo de Pitanga, SP. Inst. de Geociências e Ciências Exatas, Universidade Estadual Paulista, Dissertação de Mestrado, $121 \mathrm{p}$.

Manuscrito A-1364

Recebido em 14 de agosto de 2002

Revisão dos autores em 25 de novembro de 2003 Revisão aceita em 30 de novembro de 2003 